\title{
Perceptions about Decision Making in Entrepreneurship from the Perspective of Community Participants in Accra, Ghana
}

\author{
Marijke A. A. Okyireh
}

\begin{abstract}
In this paper, we explored the experiences of twelve (12) community participants in the La-Nkwantanang municipality (Accra) on when deciding for entrepreneurial activities. These participants were purposively selected from a previous study on entrepreneurial cognitions. The data was analysed using thematic analysis. The results of the study identified three major themes; perceptions attached to entrepreneurial activities; perceptions of past entrepreneurial experiences on decisions towards future venture creation; and potential challenges in decision-making for entrepreneurial businesses emerged from the narratives. Implications of the findings are discussed for theory and practice.
\end{abstract}

\section{Keywords - Entrepreneurial decision making,} Entrepreneurial experiences, Perceptions, Ghana

\section{INTRODUCTION}

In recent times, deciding to start a business venture have become a topical issue because of the rates of unemployment as well as the differences in the participation of entrepreneurial activities across the globe [12]. The [12] indicates that necessity motivated factors for starting enterprises form $23 \%$ whilst opportunity motivated factors form $47 \%$. This suggests that the conditions that trigger entrepreneurship are geared towards opportunities available to the individual than an individual evaluating the business as a means of survival. In view of this, some scholars have initiated moves to investigate how people make decisions for venture creation and the factors that affect entrepreneurial decision making (e.g. [2]).

Perceptions about entrepreneurship are subjective thoughts deeply rooted in a person's beliefs as he or she engages directly or indirectly in a business activity [10]. These beliefs tend to influence their decision to manage business ventures in the future [14]. It has also emerged that some factors shape these experiences and this ranges from intrinsic needs through to livelihood strategies and cultural factors (e.g. [17]; [20]). Furthermore, these experiences have created a debate amongst scholars as to who qualifies to be an entrepreneur. Whilst some scholars are reporting that personality traits such as risk taking, extroversion and resilience can predispose a person to be entrepreneurial, others have found that self-motivating traits such as "persistence", "optimism" enables an individual choose a specific entrepreneurial industry (e.g. [2]; [10]).

In Ghana, there is the belief that entrepreneurial activities are opted for by people with low education, the unemployed and marginalized groups and so deciding to start a business venture cause's people to form stereotypical views about the prospective entrepreneur ([6]; [10]). Additionally, there is the notion that intense efforts are needed to gather logistics for managing a business venture in a manner that yields results since such activities comes with uncertainties [3].

Currently, the returns on proceeds from small and medium scale enterprises (SMEs) of foreign and indigenous investors account for $70 \%$ of gross domestic product in Ghana. However, it has been found that more women compared to men form the majority in these enterprise establishments [3]. The reasons why these groups engage in entrepreneurial activities vary from socio cultural perspectives to operational factors ([18]; [23]). However, the issue of how people perceive these business activities have been under researched and there is the need to throw more light on it by identifying the determinants of entrepreneurial decisions.

\section{THEORITICAL FRAMEWORK}

Bandura (1991) Social Cognition Theory

Social cognition theory states that behaviour, cognitive and situational factors interact operatively and tend to influence each other. This theory serves as a framework for the study because perceptions about entrepreneurial experiences form the cognitive factors whilst past experiences are related to the situational factors is confronted with during venture creation. Both factors (cognitive and situational factors) will affect the behavior of the participant in making decisions in a new business venture.

Review of Related Studies

A plethora of studies has found that there are some factors that pose as antecedents of entrepreneurial decision-making. For instance, [20] reported that female entrepreneurs perceived themes such as competence, meaning, impact and self-determination as motivational factors that enhanced the psychological empowerment levels of women entrepreneurs in the management of future enterprises. Other studies also found that risk taking, self-confidence, desire for independence and responsibility and optimism were character traits of potential entrepreneurs and this affects their experiences in the management of entrepreneurial businesses (e.g. [10]; [21]).

[4], also opined that entrepreneurial optimism for persistence in SMEs was enhanced when cognitive styles for planning, knowing and creating activates were employed in entrepreneurial decisions. A feeling of being independent is also serves as a motivating factor when people want to engage in entrepreneurial activities [13]. 
Additionally some of the studies also mentioned the benefits (family survival needs, networking with other entrepreneurs and independence) they derived from entrepreneurship served as motivating factors for starting other businesses (e.g. [15]; [22]).

It is also important to note that some studies reported the experiences of entrepreneurs on managerial issues in business enterprises. Extracts of their narratives indicated that themes such as customer satisfaction, financial reasons, requisite skills and others were the crucial points for planning for entrepreneurial activities (e.g. [16], [6]). Furthermore, resilience capabilities were needed in making decisions in entrepreneurship (e.g. [1]; [9]).

From the studies reviewed, it can be deduced that the act of being entrepreneurial must begin with one's assessment of his capacity or competency to operate business activities. Given the fact that some studies have shown that entrepreneurs exhibit personality characteristics and intrinsic factors such as self-confidence, resilience, desire for independence and risk taking abilities, it is concluded that lacking these characteristics makes it a challenge. Also, managing a business comes with mixed feelings due to the uncertainty within the business environment. Furthermore, the findings of previous studies show that participants expect entrepreneurial businesses to thrive when they network with social environment and satisfy their customers.

\section{RESEARCH QUESTIONS}

1. What are the perceptions attached to entrepreneurial activities?

2. How do these perceptions of entrepreneurial activities influence decisions towards future venture creation?

3. What are the potential challenges of starting entrepreneurial businesses in the future?

\section{METHOD}

Participants and Procedure

Twelve participants (seven females and five males) between the ages of 27 and 63 years. Majority of the participants were married. The occupational status of the participants showed that majority of them were working in the service industry with the exception of one participant who was unemployed. The educational levels of the participants ranged from basic education to tertiary level. The religious affiliation also showed that eight participants were Christians and four were Muslims. The participants were sampled from three geographical locations (Redco, New Road-Madina and Libia Quarters) within the La-Nkwantanang municipality of Accra, Ghana. The participants were asked what the concept entrepreneurship meant to them and the extent to which these perceptions influenced their decision to set up new businesses. They were also asked whether there are any potential challenges. The interview sessions were audio taped and it lasted for 50minutes after which the data was transcribed verbatim. The themes were generated from the transcribed data.

\section{ETHICAL CONSIDERATION}

Approval for the research was sought from the Ethical and Protocol Review Committee (EPRC) of the College of Humanities, University of Ghana. Four ethical guidelines were observed during the course of the study and these were; informed consent, confidentiality, voluntary participation, and debriefing.

Participants were given information sheets about the study and these sheets contained the purpose of the study, procedure, duration of the study and benefits to the participants. The participants were also informed by the researchers that the decision to partake in the study was voluntary. Finally, the participants were assured that data generated will be kept safe and password coded.

\section{ANALYSIS}

The transcribed data were analyzed with thematic analysis. According to [8], the use thematic analysis entails familiarization with the data, coding, searching for themes, reviewing and defining the themes. The researchers followed this procedure and identified the recurring main themes and the supporting themes in the transcribed data. Other researchers together with the scripts to confirm the themes that had emerged later scrutinized these themes.

\section{FINDINGS}

In summary, three themes explained the entrepreneurial experiences of the participants and these were; Perceptions attached to entrepreneurial activities, past experiences for future entrepreneurial decision-making and potential challenges in decision-making for entrepreneurial businesses. Each of these themes were supported with sub themes.

\section{DISCUSSION ON FINDINGS}

The participants in this study spoke about how they generally perceived entrepreneurial activities. To these participants, the idea of starting a business meant one should be selfmotivated, a risk-taker, a networker and self-determined. The participants also believed that venturing into business activities was a means of survival

\section{Self-Motivation}

Majority of the participants' perceived entrepreneurship as an activity, which can be managed solely from an individual's own, inspired thoughts. The responses of these participants reiterated the popular adage that "each one for himself, God for us all". Thus, entrepreneurship begins when one is intrinsically motivated or when people look at success stories of others and try to emulate them. As observed by [25], [26] an individual needs to develop cognitive structures which will make him or her friendly towards venture creation opportunities. In addition, it is evident that for someone to think of entrepreneurship as a means of work, issues of the worth of the business to the operator (individual) needs to be established. Other participants also opined that the source of their intrinsic motives for engaging in an entrepreneurial business was the flexible nature of work schedules where the operator can control their own time and the management of the activities within the business. [13] also reported that 
independent motives such as the liberty to dictate one's own working hours and other intrinsic motives influence decisions to act entrepreneurial.

In the quotes below a manager shared his perception:

"I was working as a civil servant in Accra.... and saw how people were struggling and not making time for family and so because of job, I decided to do something on my own after I read a book titled McDonalds, the story made me learn a lot on making successful business ...I was inspired from there" (Male, 45 years).

This participant was motivated to start his business by reading the story of a successful entrepreneur. Below, a trader and a seamstress also shared their perception in the same direction:

"My mother took us through some internal training when we were young and so in growing up there has always be a strong motivation to do something for myself..." (Female, 36 years).

"I and my husband worked in the public service for more than seven years. I was a cleaner and he was a clerk. He decided we start something on our own...... where no rules exists and we can control the activities in the business I told myself I need to keep body and soul together to let this new business work because it is for us ......(Female 2, 37 years).

\section{Survival}

Some of the participants also view entrepreneurship as a means of "survival". Setting up a business was a means by which families can sustain themselves as these activities would boost their financial resources to provide their basic needs. Hence, when an individual starts a business, he or she is likely to attain tangible rewards. This finding is consistent with studies such as [10] and [13]. [3], also observed the significant role entrepreneurial businesses play in helping the managers performing their financial obligations towards family members.

Below is an extract of the experience of some of the participants;

"....... You know this is my hope to feed and cloth the family. No one ooo! No one can help you ooooo...... all I can say is the family lives on these cloths I sew. It is my work and with it, I have to make sure my family is ok..." (Female, 37 years)

In the same vein, a sales attendant who had completed her secondary education and decided to work to make money for her livelihood had this to say:

“......., it is all about business, making money to satisfy your basic needs and expanding the business, getting customers and the necessary advise to keep the business. My sister, for the past five years i pay my rent, bills, transport and food all come from it.........(Female, 27years).

The experiences narrated above suggest that the essence of the entrepreneurial businesses is to satisfy the fundamental needs of individuals and their families. It also reiterates the belief about the obligations of parents and priorities attached to certain family needs as explained by Maslow's hierarchy of needs, that physiological needs such as food, shelter and clothing are fundamental before other needs as presented in the circumstances above. It is therefore imperative that people go against odds to fulfill the basic needs of their family and it enhances the relationship amongst family members too. An extract of a participant response in support of this stance is as follows

"(Sigh) I know that when you do your own work it has it's issues but above all it is done so that we can feed our families even though the business may not be stable, you know that at least something will come into our pocket......... Our wives are happy when we give them some coins as chop money and this behavior will let them give you love and respect. ......(Male, 29years).

Risk taking

Generally, the participants were of the view that, entrepreneurial activities are a gamble and the chances of success cannot be assured. This implies that the decision to embark on an entrepreneurial career may expose an individual to some risks during the operation of the business or the outcome. The nature of the risk is also not static but changes from business to business. However, the issue of uncertainty remains the priority for all entrepreneurs. It must be noted that the in Ghana, people hold the global view of calculated risks in establishing businesses and this tends to impede on the propensity for success ([14]; [21]. [2] also found the nature of entrepreneurial business compels people who have high risk taking abilities to opt for manufacturing enterprises such as bottling and cannery companies, making of building materials and making of car parts whilst people with low risk abilities but are innovative opt for service enterprises such as managing restaurants, telecommunication services, hair artistry and others. Hence an entrepreneur's personal characteristics can influence his or her choice of entrepreneurial business. Although studies have supported this claim, other studies observed contradictory findings. [27] found that when entrepreneurial activities are carefully planned by forecasting uncertainties in the future coupled with specific goals, risk is eliminated.

\footnotetext{
"Hmmmm........ i think entrepreneurship can be dangerous sometimes which can spoil your business. As I told you earlier on, the business can put you into trouble ...some of the customers may pretend they are angels when they are not ......Ahhhhhh!!!!!!.I was once tricked to give some items in my madam's shop on credit and the person never showed up again. (Male, 34years).
}

"......my vehicle was not like that ....sometimes the car can break down when you have people in it.......... especially in a place where you don't get help the passengers can give pressure to pay their lorry fare...........imagine if you have used all the fare for petrol for the journey when you are going on a long journey, I pray the bus does not stop near a thieves can time you and rob you of your items........" (Male, 38years).

Networking 
Furthermore, networking according to the participants was critical to the success of the business. Some participants believed it as an opportunity to utilize their network ties to develop a career, and periodically consult these relations for advice to enhance their business. This meant that, contacting people with business ideas were very possible hence impacting positively on the development and maintenance of the business ([14]; [15]). In addition, no business survives without proper network of friends, family and experts, as they are the people who play a crucial role towards the success of the business [1]. Family members, social institutions and experts give technical advice such as where to locate the business, manage operations as well as distribute finished goods. [3], opined that the members of an entrepreneur's network are present at different processes of the business to give emotional support and psychological support for any eventualities that may occur.

Yes I got this experience from some friends and I must say that I was working with him because he introduced me to the work............ how to maintain the customers and where to get the items very cheap for profit........ In the same way, if I have problem I see them for advice...." (Male, 29years).

"I believe that entrepreneurship is about learning from people who are skilled in the area...I quite remember that once I attended some training organized by some people years back. Later I heard it was women's world banking who planned everything and that is where I got my ideas for the business... how will people understand the work if they don't get this training? (Female, 63 years).

\section{Self-determination}

From the participants' view, executing an entrepreneurial business starts with a self-reflection of the individual on his capabilities and the willingness to seek alternatives to make the business survive. During the reflection mood, if it emerges that the individual has the autonomy to opt for career alternatives which are feasible, he does so to enhance the performance of his business ([20]; 22]). Furthermore, it implies that an entrepreneur's thoughts about independence when making decisions can influence entrepreneurial persistence (e.g. [4]).

“...Day in day out I am trying hard to make some money because of that I am a mechanic and a driver at the same time so it was through repairing of people's car that I became a taxi driver. I have learnt the two jobs because I want people to know that I am serious with what I do and it has expanded my business... These two jobs when one is common I do it ....... Sometimes when people come to me with car problem too I repair it.......anytime people don't bring their car for repairs, others see me for taxi driving services ........ with things like this you always have to force and force so that your hand can go into your mouth......." (Male, 38 years).

This view is also shared by another participant, a mechanic, as he spoke of how determined he is to specialize in his business and his willingness to seek alternative means in order to reach maximum satisfaction.

"I have learnt a lot of handiwork skills like masonry, electricals..... but none was good for me until I learnt the way to fix cars. I saw an improvement in my life when I started learning how to repair cars for now it is good but when a new business comes again I will learn that one too so that things will not be hard for me..." (Male, 29 years).

Past experiences for future entrepreneurial decision-making Participants opined that their experiences in previous business entities will count towards deciding to operate other entrepreneurial businesses in the future. This generated subthemes such as Optimism, Resilience and Customer service.

\section{Optimism}

The participants were of the view that evaluating past experiences in a positive manner will enable them to manage future businesses well. This implies that optimism is crucial to the development of entrepreneurial decisions and stimulating budding entrepreneurs with enthusiastic thoughts about entrepreneurial careers can enhance venture creation intentions. This finding has been confirmed by previous studies (e.g. [22]).

Extracts of the narratives of the informants are stated below;

"...I can do it very well because I have gathered a lot of experience in my current enterprise and so I will get more ideas to help me operate the new business. As you can see me by the roadside, tomorrow I will be in a container small! Small! It will happen......" (Female, 36years).

A mechanic and a driver also re-echoed similar thoughts by expressing their belief in their ability to improve their performance over a certain period in a future business as depicted in the extracts below:

"As I had started this business, a lot have happened in it so I have got enough experience which will make me succeed........ all the mistakes have been corrected now and so I think I will perform well next time when I get the opportunity to set up another fitting shop....." (Male, 29 years).

\section{Resilience}

In exploring the extent to which past experiences can determine the decision to start businesses in the future, participants believed that developing a resilient character is critical to the survival of the business. For instance an inference from the participants' account showed elements of frustration in management procedures of the business and how the strategies are adopted to overcome the challenges in order to improve the performance of the business. Other participants also alluded to the fact that their relationship with their business counterparts resulted in the formation of resilient personalities which will help them to accomplish similar tasks in the future. The issue of resilience in entrepreneurship is also consistent with studies which have shown that people resort to resilience strategies when managing business activities in order to enhance performance [1]. [9], found that entrepreneurial resilience involves preserving existing structures for adaptability in the business environment in order to ensure continuous planning.

A bar operator shared her experience:

"Infact I was in the civil service and I had to back out to do this business ..... I did and succeeded. At the start of my 
business, I told myself that nothing comes easy especially when there was change of location, it affected slightly but am still feeding my family" (Female, 63years).

The participant (bar operator) was very emphatic that despite the challenges she envisaged, she was determined to make sustain the business. Clearly this point made by the participant shows the extent to which the challenges faced in business can change the personality characteristics to adapt to either good or bad situations.

Another participant, a graduate assistant, also spoke of how her experience of working with an entrepreneur who groomed her for the business has toughened her for a similar task. She shares her experience:

"Looking at where I am coming from, I have really struggled to make money especially when I did some work for my madam, the problems that I got (paaaaa)..... Now I am not worried at all because whatever the problem is be it money, labour or materials I can handle it I am not afraid at all....... ."(Female, 28 years).

The participant's use of "paaaa" in the quote is an Akan language which symbolizes the intensity with which she encountered problems with her madam. Although she describes the nature of the problems, she does so to show how it has strengthened her for managing her own business in the future.

\section{Customer Service}

The participants indicated that their relationship with customers was crucial and can affect the way business plans will be made in the future. This means that the customers impacted their business in several ways such as the brand of the business, profit margin and the sustenance of the business generally. This finding was consistent with studies which observed that customers were the main dictators of small and medium scale expansions ([6]; [16]) and this view seems to hold the foundations of business set-ups.

Here are quotes from two participants:

“......hmmm I suffered to get people to like my item so, $i$ will first establish a relationship with the customer and from there try to talk to them on what they need so that I can supply to them and look for ways to get them satisfied..... as I have said this is always on my mind and I pray that I never forget that customers should always be the first to be considered......"(Male, 29years).

"the making of a business in my view depends on three things customer care, standards and money. Customers should always be thought of when planning for another business. I have managed to provide standards my customers like, based on their complains and it has resulted in an increase in daily sales...... As is always said customers are always right without them we are nothing and my future business will look at that" (Male, 45 years).

The responses described above suggest that entrepreneurs have a clear purpose for the establishment of businesses and how to get those objectives achieved. [5], observed that, most businesses have the popular view of customer first though there may be other aspects of the business which may require equal attention.
Potential Challenges in Decision-Making for Entrepreneurial Businesses

The participants also envisaged that they will encounter challenges when making decisions concerning their businesses. Based on their past experiences, they recounted challenges that were related to gender, culture, skills, market fluctuation and financial obligations. They further narrated that these challenges could affect the sustenance of their career. The themes are expounded below.

\section{Gender Related Challenges}

Gender-related challenges present diverse dialogues in entrepreneurship as the issues are related despite the different types of businesses. According to [10], in Ghana, gender issues tend to be one of the most common phenomena in the area of stereotypes as opined by the participants. People prefer to see females in the frontline of business activities such as playing a mediating role between the enterprise and distributing goods and services. Males are on the other hand are seen in manufacturing and repair industries. These assertions according to the participants hinder the success of the business as it may customers' turn to prefer the opposite sex in rendering of services. Hence, it is suggested that perceptions about specific gender roles in enterprises cannot be overlooked especially in cases where the occupants to create setbacks for the businesses [23] abuse these roles dictated by society. These characteristics found in the Ghanaian setting also make avowals that gender related issues are dominant in the entrepreneurial discourse ([10]; [17]). Although some studies have discounted this claim by stating that perceptions of the duties assigned to individuals depend mainly on the remuneration attached, the way and manner individuals adapt to these roles has pronounce consequences for the business [3].

Excerpts of some of the quotes are as follows;

"........... when customers come and a male is serving a male, sometimes they make a request for female to come and serve them. The customers tell me this work is for women and they work differently than the men so they (women) understand them more" (Male, 45 years).

“.......the work $i$ am doing is a man's work and so a few women are involved in this. It is often difficult for women to engage in this kind of venture...Any woman who attempt it ayayaayah!!!! people will laugh at her papaapa........ (Male, 29years).

\section{Culture}

Cultural elements such as language and ethnicity impact the operation of businesses in Ghana. The participants' experiences of language as a challenge make it unblemished that same language tends to foster some interconnection amongst people with similar mother tongue. Also it may enhance the business operations of the business and again affects relationships with the potential customers of the enterprise. This notion according to some participants is important in making the business flourish. Some studies (e.g. [22]) acknowledge the fact that, same language between people help to make transactions easier and faster.

Again, ethnicity also has connections with business survival as articulated by the participants and it is believed the 
members of the same ethnic enclave have the tendency to explore business opportunities together [7]. The narrative expressed on ethnicity mean that, once there's a common ground (i.e. tribe or ethnicity), business can thrive and a lack of it can adversely hurt the business in the long term. Contrary to this view, other participants assessed the impact of ethnicity as average. This was because the impact of ethnicity can be unassuming when the identity of the client with whom the business owner interacts with fails to disclose his town of origin [22].

"In starting a business, culture is very important you know we have different people with different languages so I think it is good to learn other languages for the sake of your business, because it's not all the customers who can speak your mother tongue. .... learning other languages will open other opportunities through the way you express yourself to the customers who come to your business... (Male, 34 years).

Another participant, a restaurant manager, also intimated that learning a few words of another language can attract people from that area to patronize your business.

"Most of my friends are Ewes and so when I speak the same language with them they keep coming and I speak a little Dagaati too and this attracts northners to my business" (Male, 45years).

\section{Market Fluctuation}

The participants also perceived the issue of unstable sales from services and goods as a challenge in decision for future businesses. Hence the theme, "market fluctuation". According to [16], uncertainty of market demands for goods hinders the operations of small businesses. Consequently, businesses fail when the market forces such as inflation, high cost of product or high tax regime work against the smooth running of the enterprise [15]. This finding was also consistent with [22] who reported that the demand and supply of goods determine pattern of scales in a business therefore an increase in the demand for the goods will increase sales and vice versa hence the changing patterns in sales.

An excerpt of the responses of two participants is shown below:

"As for such businesses I know for sure that you will not always get people coming for things. Today if it is good for you tomorrow it will be bad...It is like the weather when one day it rains another day the sun will sunshine........that is what you have to deal with before you make any move" (Female, 41 years).

\section{Financial Challenges}

The participants also foresaw financial resources as a potential challenge in decision-making. The narratives reported earlier suggest that all the participants agreed that capital is necessary to start a business and to strategize in order to enhance productivity. They also shared their experiences on documenting their business procedures in order to ensure that profits were made. Consistent with this finding, [24], revealed that access to financial resources was crucial to formation of business and hence inadequate funding posed as a treat in the management of the entrepreneurial businesses.

Below are the quotes from two participants;

"The cost of a container is an issue.... when you get it too, renting that land for the space can be costly...oh see ooo when you settle on the place then you have to fill the container with the goods to attract people............it also depends on how much you have with the "susu" people" so you really have to think of how much money you have...." (Female, 35years).

“........ some customers come to repair their cars but don't have money so you have to do it and later the person will pay..... i can say that some will pay and others too don't fulfill their promise when the car is fixed for them .Location too is a problem.... because getting one, means you have to spend......" (Male, 29 years).

Skill related challenges

The informants also for saw lack of requisite skills as a challenge in making the business thrive despite the existence of other challenges. Hiring of skilled labour in small businesses poses as a problem by some studies (e.g [6]; [19]). From the narratives presented, hiring labourers with the requisite skills was essential to the survival of business but it also posed as challenge in terms of remunerating these staff. This is because hired staff with expertise in the business field made demands for salaries which the business owners could not afford to pay on the basis of cost and sustainability. This finding was consistent with studies that have reported that most small and medium scale businesses do not hire experienced people to help manage their businesses due to their employees' salary expectations (e.g. [6]).

“....... I don't take skilled labour..... why? because, a skilled labourer wants to fix his own salary or benefits. But when I look at my setup I can't so I have to take workers who are ready to learn the job then manage it like that" (Female, 63 years).

\section{IMPLICATIONS OF THE FINDINGS}

The responses of the participants show that every individual should posse some attributes before they can become successful entrepreneurs and these attributes should range from taking risks, relating and interacting with business experts for support and strategizing to sustain one's own motivation for the business. Experiences shared by the participants also showed that they attached mixture of happiness and negative feelings to entrepreneurial activities. While some participants saw it as opportunity to be determined and motivated from their experiences, others felt it was the only means by which their families had to survive.

Additionally, the responses of the participant show that their experiences in managing existing businesses can affect decisions the establishment of new businesses. Therefore, the outcome of the business can form either a positive impression of other budding businesses or toughen the manager to develop a resistance to eventualities.

It was also seen that customers formed the core of existing businesses as well as its sustenance. Therefore, future 
ventures can only thrive when management has a good rapport with its customers.

Lastly, the findings also imply that some cultural elements can hinder the success of the business if not properly addressed. For instance, languages used in communication should be familiar to both management and customers of enterprises. Also the identification of people from the same tribe can cause business owners to form networks that can positively impact the business. From the narratives it can be said that managerial processes involved in financing and recruiting of skilled labour is crucial in deciding for new businesses.

Theoretically, it can also be said that comparing the effect of the three factors (cognitions, situational and behavior) on each other, the role of situational factors in entrepreneurship such as network systems, culture and stands tall in ensuring planning for enterprises successfully

\section{REFERENCES}

[1] Abebrese, A. (2015). Understanding entrepreneurial resilience development within institutional constraints: A case of Ghana (Doctoral thesis), Robert Gordon university, Aberdeen, United Kingdom.

[2] Acheampong, G. (2017). Beyond the EJ model: entrepreneurial orientation and industry choice of Ghanaian entrepreneurs. Journal of Global Entrepreneurship Research, 7(28), 1-10.

[3] Adom, K. (2015). Recognizing the Contribution of Female Entrepreneurs in Economic Development in Sub-Saharan Africa: Some Evidence from Ghana. Journal of Developmental Entrepreneurship, 20(1), 1-24.

[4] Adomako, S., Danso, A., Uddin, M., \& Ofori Damoah,J. (2016). "Entrepreneurs' optimism, cognitive style and persistence". International Journal of Entrepreneurial Behaviour \& Research, 22 (1), 84-108.

[5] Boadi, R. A., Boateng, R., Hinson, R., \& Opoku, R. A. (2007). Preliminary insights into m-commerce adoption in Ghana. Information Development, 23(4), 253-265.

[6] Boateng, G. O., Boateng, A. A., \& Bampoe, H. S (2014). Barriers to Youthful Entrepreneurship in Rural Areas of Ghana. Global Journal of Business Research, 8(3), 109-119.

[7] Canedo, J.C., Stone, D.L., Black, S.L. and Lukaszewski, K.M. (2014), "Individual factors affecting entrepreneurship in Hispanics", Journal of Managerial Psychology, Vol. 29 No. 6, pp. 755-772.

[8] Clarke, V. \& Braun, V. (2013) Teaching thematic analysis: Overcoming challenges and developing strategies for effective learning. The Psychologist, 26 (2), 120-123.

[9] Chu, J. H. (2015). Resilience capabilities in the face of environmental turbulence: the case of Hong Kong small to medium enterprises. (PhD Thesis), School of management, College of business, RMIT University, Hong Kong.

[10] Dzisi, S. (2008). "Entrepreneurial Activities of Indigenous African women: A case of Ghana", Journal of Enterprising Communities: People and Places in the Global Economy, 2 (3), 254-264.

[11] Engel, U., Van Burg, E., Kleijn, E., \& Khapova, S. N. (2017). Past Career In Future Thinking: How Career Management Practices Shape Entrepreneurial Decision Making. Strategic Entrepreneurship Journal, 11(1), 122-144

[12] Global Entrepreneurship Monitor (2019). Global Entrepreneurship Monitor Report. MA, United States: Babson College.

[13] Hamilton, L., \& De Klerk, N.( 2016).Generation y Female Students' Motivation Towards Entrepreneurship. International journal of business and management studies, 8, (2), 1309-8047.

[14] Jyoti, J., Jyoti, S., \& Kumari, A. (2011). Factors affecting Orientation and satisfaction of women entrepreneurs in rural India. Annals of innovation and entrepreneurship, 2(1),1-13.

[15] Khefacha, I., \& Belkacem, L. (2015). Modeling entrepreneurial decision-making process using concepts from fuzzy set theory. Journal of Global Entrepreneurship Research, 5(13), 1-2.

[16] Kwamega, M., Li, D., \& Ntiamoah, E. D. (2015). Role of Total Quality Management (TQM) as a Tool for Performance Measurement in Small and Medium- sized Enterprise (SME'S) in Ghana. British Journal of Economics, Management \& Trade, 10(3), 1-10.

[17] Mordi,C., Simpson, R. \& Singh, S.(2010). The Role of Cultural Values in Understanding the Challenges faced by Female Entrepreneurs in
Nigeria. Gender in Management:An International Journal, 25 (1), 521.

[18] Okyireh, M.A.A. (2018) Entrepreneurial cognitions: assessing the influence of cognitive styles and psychosocial factors on entrepreneurial decision making ( $\mathrm{PhD}$ Thesis),Department of Psychology, University of Ghana.

[19] Okyireh, M. A. A., \& Okyireh, R. (2017). Determinants of Entrepreneurial Decision-making among final year students in tertiary institutions. A Qualitative study. International journal of research in computer applications and management, 7(9), 74-77.

[20] Okyireh, M. A. A., \& Simpeh, K. N. (2016). Exploring the nature of Psychological Empowerment of women entrepreneurs in a rural setting in Greater Accra Region, Ghana. Journal of Business and Management Sciences, 4 (6)138-141.

[21] Pounder, P., \& Devonish, D. (2016). Understanding Entrepreneurial Attitudes, Intentions and Activity in Barbados, Caribbean Educational Research Journal, 4(1), 79-96.

[22] Shelby, T. (2017). Starting a business abroad: Perceived advantages and disadvantages of migrant entrepreneurs. A qualitative study of migrant entrepreneurs in Finland (Master's Thesis), Aalto University School of Business, Finland.

[23] Shinnar, R. S., Giacomin, O., \& Janssen, F. (2012). Entrepreneurial Perceptions and Intentions: The Role of Gender and Culture. Entrepreneurship theory and Practice, 36(3), 465-493.

[24] Ssendi, L. B. (2013). Entrepreneurship activities in rural Tanzania: understanding women's micro businesses (Doctoral thesis. Robert Gordon University, Aberdeen, United Kingdom). Retrieved from: http://openair.rgu.ac.uk

[25] Urban, B (2008). Associations between entrepreneurial empowerment and reasons for self-employment. SAJEMS NS, 10(3), 313-329.

[26] Urban, B. (2010). Cognitions and motivations for new venture creation decisions: linking expert scripts to self-efficacy, a South African study. The International Journal of Human Resource Management, 21(9), 1512-1530.

[27] Vershinina, N., Barrett, R., \& McHardy, P. (2017)."Logics and Rationalisations underpinning Entrepreneurial Decision making", Journal of Small Business and Enterprise Development, 24 (1), 158175.

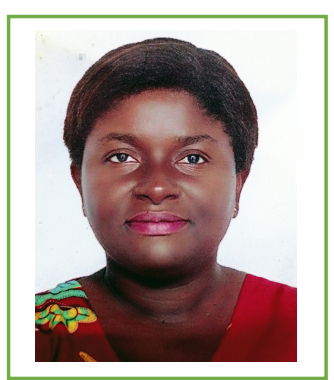

Marijke Akua Adobea Okyireh (PhD) is a Psychology and Entrepreneurship lecturer with the University of Professional Studies, Accra. She has several peer reviewed articles in the area of Entrepreneurship with Psychology underpinnings. She holds a PhD in Social Psychology from the University of Ghana and also a member of the Ghana Psychology Council, Ghana. 